\title{
Optimal Implementation of Wastewater Reuse in Existing Sewerage Systems to Improve Resilience and Sustainability in Water Supply Systems
}

\author{
Aakash Dev ${ }^{1}$, Timo C. Dilly ${ }^{2}$, Amin E. Bakhshipour ${ }^{2, *}$, Ulrich Dittmer $^{2}{ }^{-}$and S. Murty Bhallamudi ${ }^{1}$ \\ 1 Indian Institute of Technology, Madras, Chennai, Tamil Nadu 600036, India; \\ dev.aakash1794@gmail.com (A.D.); bsm@iitm.ac.in (S.M.B.) \\ 2 Department of Civil Engineering, Institute of Urban Water Management, University of Kaiserslautern, \\ Paul-Ehrlich-Str. 14, 67663 Kaiserslautern, Germany; timo.dilly@bauing.uni-kl.de (T.C.D.); \\ ulrich.dittmer@bauing.uni-kl.de (U.D.) \\ * Correspondence: amin.bakhshipour@bauing.uni-kl.de
}

\section{check for} updates

Citation: Dev, A.; Dilly, T.C.; Bakhshipour, A.E.; Dittmer, U.; Bhallamudi, S.M. Optimal Implementation of Wastewater Reuse in Existing Sewerage Systems to Improve Resilience and Sustainability in Water Supply Systems. Water 2021, 13, 2004. https://doi.org/10.3390/ w13152004

Academic Editors: Robert Sitzenfrei, Kegong Diao and David Butler

Received: 15 June 2021

Accepted: 19 July 2021

Published: 21 July 2021

Publisher's Note: MDPI stays neutral with regard to jurisdictional claims in published maps and institutional affiliations.

Copyright: (c) 2021 by the authors. Licensee MDPI, Basel, Switzerland. This article is an open access article distributed under the terms and conditions of the Creative Commons Attribution (CC BY) license (https:/ / creativecommons.org/licenses/by/ $4.0 /)$.

\begin{abstract}
A transition from conventional centralized to hybrid decentralized systems has been increasingly advised recently due to their capability to enhance the resilience and sustainability of urban water supply systems. Reusing treated wastewater for non-potable purposes is a promising opportunity toward the aforementioned resolutions. In this study, we present two optimization models for integrating reusing systems into existing sewerage systems to bridge the supply-demand gap in an existing water supply system. In Model-1, the supply-demand gap is bridged by introducing on-site graywater treatment and reuse, and in Model-2, the gap is bridged by decentralized wastewater treatment and reuse. The applicability of the proposed models is evaluated using two test cases: one a proof-of-concept hypothetical network and the other a near realistic network based on the sewerage network in Chennai, India. The results show that the proposed models outperform the existing approaches by achieving more than a $20 \%$ reduction in the cost of procuring water and more than a $36 \%$ reduction in the demand for freshwater through the implementation of local on-site graywater reuse for both test cases. These numbers are about $12 \%$ and $34 \%$ respectively for the implementation of decentralized wastewater treatment and reuse.
\end{abstract}

Keywords: urban water supply systems; hybrid decentralized systems; resilience; sustainability; optimization; on-site graywater treatment; water reuse; decentralized wastewater treatment

\section{Introduction}

The urban water supply sector in many developing countries such as India is suffering from a serious supply-demand gap. Although the benchmark domestic per capita water supply in India is $135 \mathrm{~L}$ per capita per day (lpcd), the actual per capita supply of water in Indian cities ranges from 37 to 298 lpcd for a limited duration [1]. There is a continuous stress on existing water resources and failure to develop new sources at a rapid pace. For example, the City of Chennai declared 19 June 2019 as "Day Zero" for the availability of fresh water [2]. This stress can be attributed to not only an increase in per capita water consumption resulting from an increase in the standard of living but also an increase in the total demand due to population growth [3].

At present, the urban population of India stands around $31 \%$, and it is expected that by 2025 , nearly $46 \%$ of the population of India will be staying in urban areas [4]. Hence, there is an indispensable need to conquer this supply-demand gap in the domestic water supply to provide more sustainable and resilient methods of service delivery. Butler et al. (2014) [5] defined resiliency as "the degree to which the system minimizes the level of service failure (magnitude and duration) over its design life when subject to exceptional conditions". Due to the dependence on a limited number of water supply sources and 
the hierarchical network structure, centralized water systems are more vulnerable, less resilient, and adaptable to upcoming threats such as changing precipitation pattern and unexpected climate disasters such as prolonged floods or droughts $[6,7]$.

Recent literature highly recommends transitioning away from fully centralized, as the new paradigm is toward resilient, adaptive, and sustainable urban water systems $[6,8,9]$. As a response, there have been open-ended tries to develop frameworks and tools for decentralized urban water management [6,10-13]. For example, innovative design strategies and frameworks for the integration of decentralized rainwater management measures [14-19] or for the decentralized treatment and management [10,20-22].

Hybrid decentralized urban water systems refer to small and medium-sized water infrastructure that employs locally available water sources including gray water and stormwater runoff, and they work individually or joined with conventional water infrastructure. Employing multiple water supply sources grants higher resiliency by reducing the vulnerability of the system to both abrupt failures and gradual changes. By design, these systems have a better potential to cope and adjust: they can draw on a diversified portfolio of water sources, enhance system buffer ability by lessening potable water demands, and employ multi-scale networks and pathways [23,24]. Hybrid decentralized system components that are geographically scattered and individually operated also offer safe-failure features by narrowing the consequences of system failures to smaller areas and preventing a domino effect of failure among other system components [25].

Reusing of treated wastewater for non-potable purposes such as toilet flushing, gardening, automobile washing, etc. is considered as one of the sustainable ways of reducing the fresh water demand [26]. Apart from the non-potable needs of the domestic population, wastewater reuse can also be used to substitute water required by industries and by municipalities for green area maintenance. Although the idea of reusing wastewater for domestic usage has been around for a long time, its practice has not received much acceptance due to several reasons [27]. The main reasons for anxiety regarding the reuse of wastewater are fear that reused water contains more pathogens and chemicals than the freshwater, and individual mindset. However, as argued by Voulvoulis (2018) [28], wider acceptance of reused wastewater may be achieved by transitioning to a circular economy. Nika et al. (2020) [29] recently provided a general circularity assessment framework for complex water systems. Recently, Yoonus and Al-Ghamdi (2020) [30] compared the life cycle environmental advantages of installing a local on-site graywater reusing system with the conventional water treatment system of desalination. Their results showed that the graywater reusing system produced less $\mathrm{CO}_{2}$ than the conventional desalination system, and wastewater reusing can have a positive impact on the environment compared to conventional methods.

One can think of implementing wastewater reuse into existing sewerage systems in order to fill the immediate demand-supply gap in water supply systems in areas of severe water scarcity. However, such implementations should weigh the benefits accrued due to a decrease in the demand for freshwater against the cost of implementation of the wastewater reusing scheme and also the detrimental effect, if any, on the operation of the existing sewerage systems. Deepika et al. (2011) [26] designed and implemented the graywater reusing for an urban locality in Nagpur city in India. They provided the complete cost breakdown including capital costs, operation cost, energy cost, and labor costs. It was observed that there was a reduction in the demand of fresh water in the locality by $48 \%$ after the implementation of graywater reuse for toilet flushing and garden irrigation. Penn et al. (2012) [31] demonstrated that graywater reuse reduced the wastewater flows by 25 to $40 \%$. However, it was found that after implementation of graywater reuse, the increase in contaminant load was not as expected. There was a reduction in demand for fresh water by $26 \%$ when treated graywater was used for toilet flushing only and by $41 \%$ when it was used for both toilet flushing and garden irrigation as compared to a non-reusing house.

Penn et al. (2013) [32] modeled a representative sewer system located near the coast in central Israel and analyzed the effect of different levels of graywater reuse on the hydraulics 
of sewer flows using the SIMBA simulation system. Different configurations of graywater reusing scenarios and distributions of graywater reusing houses were considered. The flow, velocity, and depth decreased with an increase in graywater reusage, with a reduction mainly in the morning peak. Their study indicated that the sewer blockage rates were not increased significantly. Later, Penn et al. (2014) [33] developed a solid transport model to assess the effects of graywater reuse and water-efficient toilets on the upstream and downstream ends of the sewer system. Their results showed that if reusing is high at the upstream end, there was no solid movement for $76 \%$ (18.2 h) of the day. However, the downstream end was not affected due to additional wastewater flows, and full movement of the solids was detected. In a further study, Penn et al. (2017) [34] considered stochastic inputs for wastewater flows and solids movement. The results from this study reinforced the observations that were made in their previous study. Their study indicates that the implementation of reusing into an existing sewerage system need not be uniform spatially.

Based on the scale of demand-supply gap, cost of fresh water supply, cost of wastewater treatment, and operating constraints in the existing sewerage system, reusing may not be the most economically feasible option available always. This presents the need for an optimum implementation. Penn et al. (2013) [35] developed a multi-objective optimization problem for optimally distributing the different configurations of graywater reusing houses i.e., a house with no graywater reusing, graywater reusing only for toilet flushing, and graywater reusing for both toilet flushing and garden irrigation. The objective functions included the minimization of total wastewater flow at the outlet of the sewer system and the cost of onsite treatment of graywater. The constraints included the wastewater flow velocity. Zhang et al. (2014) [36] developed a multi-objective optimization model for sustainable wastewater reuse and for water policy making in China. The three objectives were: (i) maximization of wastewater reuse, (ii) minimization of cost, and (iii) maximization of pollution reduction. Studies carried out by Penn et al. (2013) and Zhang et al. (2014) [36] did not link up the implementation of wastewater reuse with the benefits that are obtained in terms of decrease in fresh water cost. In addition, they did not consider the implementation of wastewater (gray- and blackwater) reuse in an existing sewerage system.

Newman et al. (2014) [37] developed a comprehensive model for planning and designing green field water systems. Their optimization model considered alternate water sources including localized water sources such as graywater reusing and rainwater harvesting, different configurations from sources to end use, and different levels of decentralization. The optimization model produces a tradeoff between cost of water supply, water savings, and greenhouse gas emissions. The results indicated that local water systems can reduce the fresh water supply by as much as 54\%. Recently, Basupi (2021) [38] developed a multiobjective optimization problem for analyzing cost benefits between separate water-saving schemes (WSS) and integrating WSS with the sanitary sewer system design. The objective function included the minimization of total cost and maximization of cost benefits. The results showed that the integrated design gave less cost benefit as compared to separate water-saving schemes for a similar total cost. Optimization models developed by Newman et al. (2014) and Basupi (2021) [38] dealt with the development of green field systems and did not consider the optimal implementation of wastewater reusing into existing sewerage systems.

Although the implementation of wastewater reusing has been discussed extensively in the earlier literature, the problem of optimal implementation of wastewater reusing into existing sewerage systems has not been addressed completely. To the authors' knowledge, earlier works did not consider the overall economics in detail, wherein the benefits of reducing the freshwater consumption are explicitly considered along with the dual piping system cost and pumping cost, which have an important bearing on the economic viability of retrofitting an existing sewerage system with decentralized wastewater treatment for reusing. In this paper, we present two simple-to-use screening models at the planning stage for the optimal implementation of wastewater reusing into an existing sewerage system to achieve the goal of reducing the stress on existing urban water supply systems. The first 
model addresses the optimal implementation of local on-site graywater treatment and reuse, while the second model addresses optimal implementation of decentralized wastewater (gray- and blackwater) treatment for reuse. We present the details of formulation of the optimization model, proof-of-concept demonstration, and illustration of application to a realistic system in the following sections.

\section{Materials and Methods}

Two optimization models are formulated for planning the introduction of reusing systems into existing sewerage systems in order to bridge the supply-demand gap in an existing water supply system. In Model-1, the supply-demand gap is bridged by introducing on-site graywater treatment and reuse, while in Model-2, the supply-demand gap is bridged by decentralized wastewater treatment and reuse. Details of model formulations are presented in the following sections.

\subsection{Model-1: On-Site Graywater Treatment and Reuse}

The purpose of introducing a local on-site reusing system is to treat the not-so-polluted graywater using economical treatment systems that have become available at present and then reuse this treated graywater locally to meet the non-potable water needs. This is suggested with the intention of reducing the demand for fresh water as well as reducing the price paid for water bills. However, this has a negative effect on the functioning of the existing sewerage network because of a reduction in the flow rates in the sewers. Reduction in the flow rates reduces velocities, increases the chances for the deposition of solids, and subsequently increases the operation and maintenance cost of the sewerage system. Introduction of on-site graywater treatment and reuse will also require capital expenditure. Therefore, the decision on scale of implementation of graywater reuse is not straightforward and needs optimization.

A hypothetical wastewater collection system as shown in Figure 1 is used to illustrate the model formulation and its implementation. This system is a gravity flow separate system. In this collection network, flow from all the nodes is directed toward the centralized wastewater treatment plant. In this network, a node represents (i) the point that caters to the water needs of a cluster of users, (ii) the point where waste water is generated, and (iii) the possible location for on-site graywater treatment and reuse. This network is provided as input to the optimization model in the form of an incident matrix. The diameter, the length, the roughness coefficient and the slope of each sewer (link connecting the nodes) are provided as input. Populations served by each node are also specified. Per-capita demand for water is 135 lpcd, as per the norm in India (Water Aid India, 2018).

In the optimization model, the decision variables are fractions of total graywater generated at any node I, which should be treated $\left(F_{i}\right)$ and reused at that node. The total number of nodes $=N$. Consider the mass flow diagram at each node, as shown in Figure 2 . Here, $D_{t w}=$ total water demand at any node, $R_{f}=$ the fraction of water supplied that comes out as wastewater, and $\alpha=$ fraction of wastewater that is graywater.

It can be seen from Figure 2 that the amount of fresh water supply at any node $=\left(1-F \times \alpha \times R_{f}\right) \times D_{t w}$, while the amount of treated water supplied at any node $=F \times$ $\alpha \times R_{f} \times D_{t w}$. The amount of wastewater going into the sewer system at any node $=R_{f}$ $\times D_{t w} \times(1-\alpha \times F)$. The objective function in the model is minimization of the total cost, $Z_{1}$. The total cost comprises of: (i) cost of fresh water supplied; (ii) cost of treated graywater supplied; (iii) capital cost of graywater treatment plants; and (iv) operational cost of flushing in any sewer in case the velocity in the pipe, $V_{p}$, falls below the self-cleansing velocity. In India, a self-cleansing velocity $0.6 \mathrm{~m} / \mathrm{s}$ is stipulated, based on the design of sewers for peak flow rates. The peak flow rates are obtained from the daily average flow rates multiplied with the peak flow factor. Mathematically, the above-mentioned optimization problem can be expressed as follows.

$$
f_{\text {opt }}=\arg \min _{f \in \mathrm{F}}\left[Z_{1}\right]
$$




$$
Z_{1}=\sum_{i=1}^{N}\left(D_{t w}\right)_{i} \times\left[\left(1-W_{i}\right) \times C_{f}+W_{i} \times C_{r}\right]+\sum_{j=1}^{M} A_{j} \times V_{f l} \times t_{f l} \times C_{f l} \times \delta_{j}+C R F \times \sum_{i=1}^{N} C_{t p} \times X_{i}
$$

in which $Z_{1}$ is the objective function, $f$ represents the decision variables, $f_{\text {opt }}$ is an optimal solution, and $F$ is the feasible space of the problem. In addition, $W_{i}=$ fraction of water demand that is met through reusing, $C_{f}=$ unit cost of fresh water, $C_{r}=$ unit cost of reused water, $A=$ area of cross-section of any sewer, $V_{f l}=$ flow velocity during the flushing, $t_{f l}=$ time of flushing, $C_{f l}=$ unit cost of water used for flushing, $C_{t p}=$ unit cost of treatment plant, $X=$ treatment plant capacity, and $\delta=$ Dirac Delta function, which is equal to 1 if the velocity in the pipe during peak flow $V_{p}$ is less than self-cleansing velocity of $0.6 \mathrm{~m} / \mathrm{s}$, and it is equal to zero otherwise. $N=$ total number of nodes and $M=$ total number of sewers. Costs are determined on annual basis.

$$
W_{i}=R_{f} \times \alpha \times F_{i}
$$

The capital cost of treatment plant is converted to annual cost by multiplying it with capital recovery factor, $C R F$.

$$
C R F=\frac{I \times(1+I)^{N_{y}}}{(1+I)^{N_{y}}-1}
$$

in which $I=$ interest rate and $N_{y}=$ design period for the project. It can be seen that as the value of $F_{i}$ increases, the cost of supplying the treated water will increase, but the cost of supplying the fresh water decreases. In addition, the required treatment plant capacity will increase, and therefore, so will the capital cost of treatment plants. It should also be noted that the rate at which wastewater flows into the sewerage system at any node $i, Q_{s i}$, will reduce.

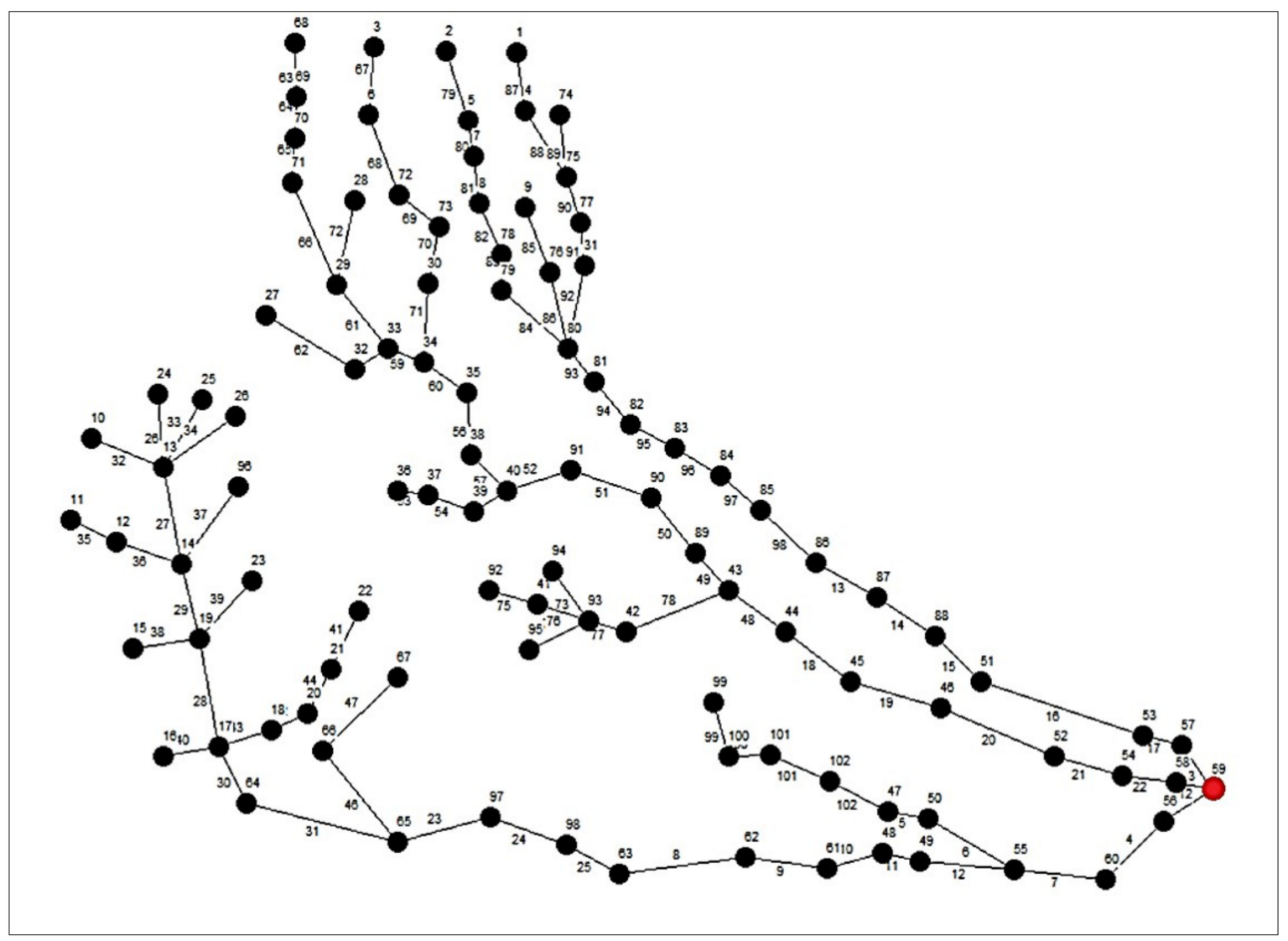

Figure 1. Illustrative wastewater collection system. 


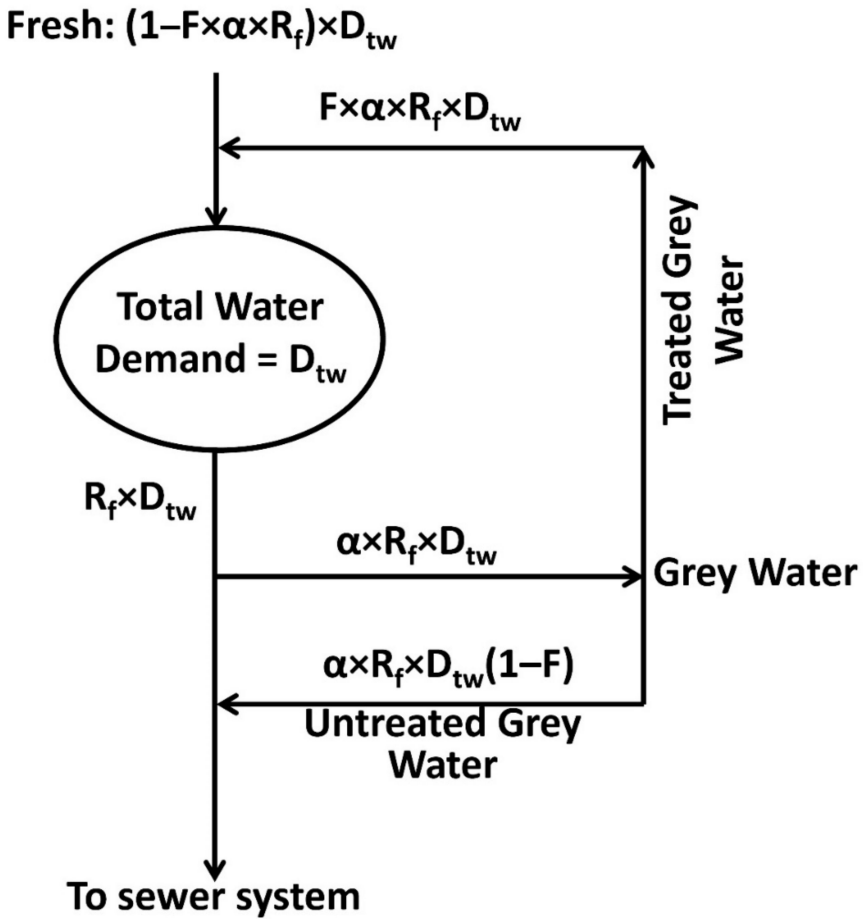

Figure 2. Schematic for mass flow balance at any node i.

$$
Q_{s i}=R_{f} \times D_{t w} \times\left(1-\alpha \times F_{i}\right)
$$

This may reduce the velocities in sewers below the self-cleansing velocity, making it necessary to arrange for flushing in those sewers. This will increase the flushing cost. Thus, it can be seen that the objective function is a function of decision variables $F_{i}$ for $i=1$ to $N$. Constraints in the optimization model are as follows.

1. There may be upper and lower bounds on the fraction of graywater that may be treated.

$$
F_{\text {min }} \leq F_{i} \leq F_{\max } \quad \forall i=1 \text { to } N
$$

2. Although a flushing mechanism will be provided for all those sewers where the velocity $V p$ is less than the self-cleansing velocity, still a constraint is stipulated on the minimum velocity required.

$$
V_{p j} \geq V_{\min } \quad \forall j=1 \text { to } M
$$

3. As has been mentioned already, we are interested in a screening model for use at the planning stage. It is assumed that pseudo steady uniform flow conditions exist during the peak flow [39]. Velocities in each sewer for peak flow conditions are obtained by solving the Manning flow equation for free surface flow conditions. Therefore, the equality constraint for hydraulic conditions in each sewer can be written as

$$
V_{p j}=f\left(Q_{j}, D_{j}, S_{j}, n_{j}\right) \quad \forall j=1 \text { to } M
$$

in which $Q=$ flow rate in the sewer during peak flow condition, $D=$ diameter of sewer, $S=$ slope of the sewer, and $n=$ Manning roughness coefficient. The flow rate in any sewer depends on the network connectivity (Figure 1) and the waste water input 
into the system at each node, which in turn depends on the water demand at that node and the fraction of graywater treated. This equality constraint may be written as

$$
Q=g_{1}\left(\text { network connectivity, } R_{f} \times D_{t w} \times(1-\alpha \times F)\right)
$$

The authors have developed a MATLAB $\odot$ program for determining the flow rates in sewers as a function of network connectivity, water demands at the nodes, $D_{t w}$, and the decision vector $F$, using the concept of ancestral nodes. This MATLAB@ program also solves the Manning's equation to determine the velocity and depth of flow in each sewer by taking $Q$ and sewer characteristics $(D, S$, and $n)$ as input.

\subsection{Model-2: Decentralized Wastewater Treatment and Reuse}

In this model, decentralized wastewater (gray- and black water) treatment is introduced into an existing sewerage system at different available sites (Figure 3), and the treated wastewater is reused to meet the local non-potable water needs at any node upstream of it. It is also sold for the maintenance of public green areas in that locality. This is suggested with the intention of conserving the fresh water sources and reducing the price paid for water bills. However, as in the case of Model-1, the introduction of decentralized wastewater treatment may necessitate flushing in some downstream sewers in order to remove the deposited solids. It requires capital investment for a pipeline system (dual pipeline system) to transport the treated wastewater back to the nodes and also additional operation cost for pumping in the dual pipeline system.

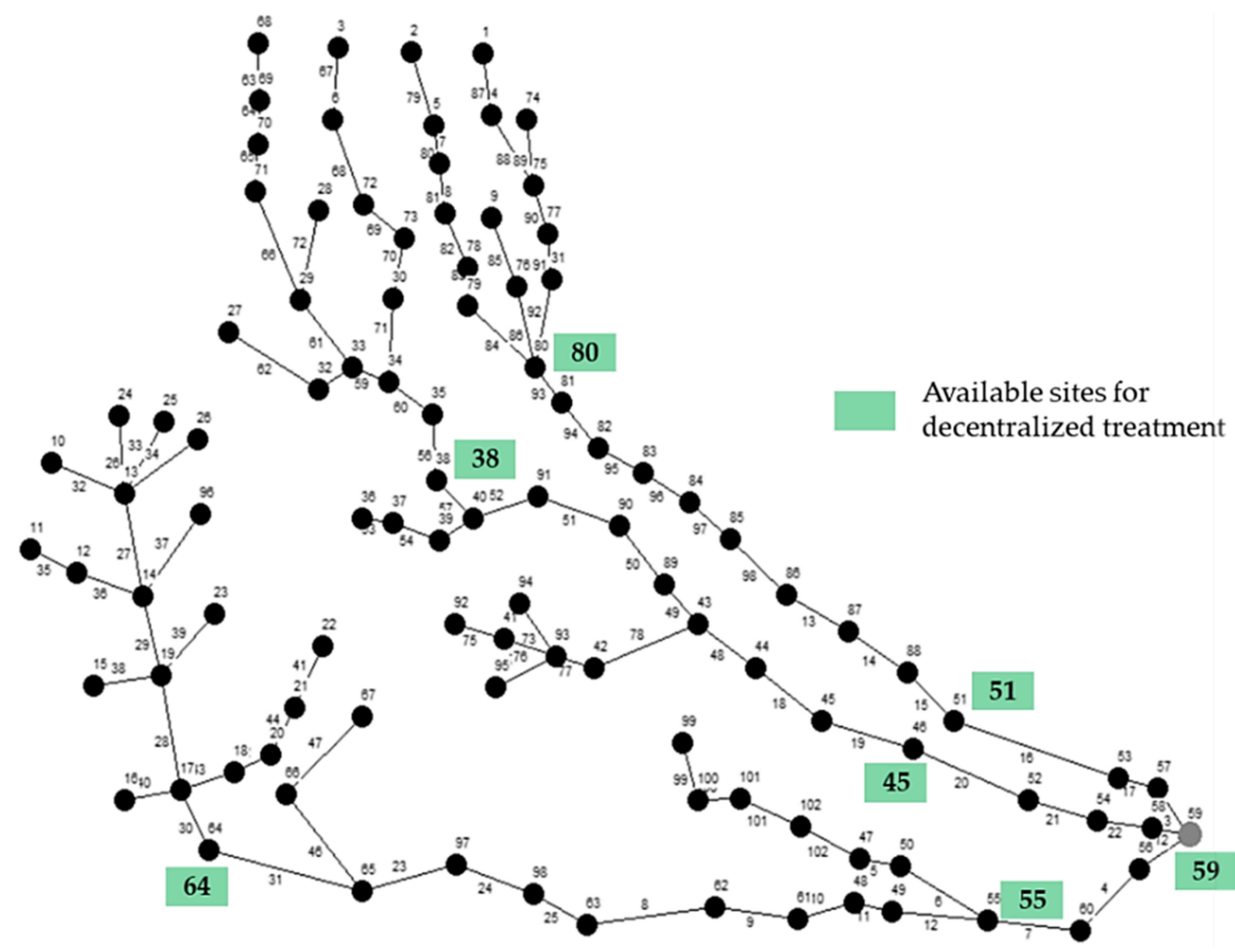

Figure 3. Illustrative wastewater collection system with locations for decentralized treatment plants. 
The amount of wastewater treated at each decentralized treatment plant should be less than or equal to the sum of local non-potable water demand and demand for green area maintenance. In addition, the treated water that is supplied locally via the dual piping system to the households at a particular site should be less than or equal to the total non-potable demand. If no fraction is treated at a particular site given as input to the model, then the wastewater is assigned to the next downstream plant, and so on. This means that the model can opt for centralized treatment if that is the most cost-effective option. It can be easily seen that the decision on the scale of implementation of decentralized wastewater treatment and reuse is not straightforward and needs optimization.

The proposed Model-2 is similar to Model-1, except that the treatment can occur only at some locations which are pre-specified (green boxes in Figure 3). However, wastewater flows into the sewerage system at all the nodes. There is no separation of graywater and blackwater. As in the case of Model-1, the network connectivity, the diameters, the lengths, the roughness coefficients, and the slopes of each sewer are provided as input. Populations served by each node are also specified. From this, the population handled by each of the decentralized sites can be computed. The maximum non-potable water demand upstream of a decentralized plant location is taken as $50 \%$ of the total fresh water demand and the demand for green area maintenance is taken as $15 \%$ of the fresh water demand at the site. However, these values can be varied based on the actual requirement specific to a case. All the other inputs to the model are the same as those discussed for Model-1.

In this model, the decision variables are as follows:

1. Optimal fractions of wastewater to be treated at each decentralized site $k$; i.e., $F_{k}$ for $k=1$ to NT. NT is equal to total number of possible decentralized locations where wastewater is treated.

2. Optimal fraction of treated wastewater that is supplied to households via dual piping system from the particular site $k$; i.e., $\beta_{k}$ for $k=1$ to NT.

The objective function in Model-2 is minimization of the total net cost, $Z_{2}$, which is the total cost minus the total benefit accrued by selling the treated wastewater. The total cost comprises of the following: (i) cost of fresh water supplied to the households, (ii) cost of treated waste water supplied to the households (treatment cost), (iii) capital cost of treatment plants, (iv) pumping cost (capital cost and operation cost), (v) capital cost of dual piping system to carry the treated wastewater, and (vi) flushing cost in the sewerage system in case the velocities are less than the stipulated self-cleansing velocity.

The proposed model does not involve a complete design of the dual piping system and pumping systems for transporting the treated wastewater to households. It is meant only as a screening level model to be used at the planning stage to make preliminary decisions on the scale of the decentralized waste water treatment and reuse that may be introduced. Therefore, the capital cost of the dual piping system and the pumping cost are determined only approximately. The approximate cost of the dual piping system is worked out as shown below.

Potential cost of the dual piping system to provide the entire non-potable water demand in the region associated with the decentralized plant at the $k$ th location is equal to $\left(C_{p}\right)_{k} \times\left(L_{p}\right)_{k}$. Herein, $\left(C_{p}\right)_{k}=$ per meter length cost of providing the dual piping system associated with the treatment plant at $\mathrm{k}$ and $\left(L_{p}\right)_{k}=$ total length of the dual piping system associated with the treatment plant at $k$. The estimated cost of the dual piping system in the region associated with the decentralized plant at $k$ th location, $\left(Z_{d p}\right)_{k}$, is obtained by reducing the potential cost proportionally, based on the actual amount of treated waste water supplied to households in that locality.

$$
\left(Z_{d p}\right)_{k}=\left[\frac{\beta_{k} F_{k} \times\left(D_{w w}\right)_{k}}{\theta \times\left(D_{w d}\right)_{k}}\right] \times\left(C_{p}\right)_{k} \times\left(L_{p}\right)_{k}
$$


in which $\beta_{k}=$ optimal fraction of treated wastewater supplied to households (decision variable), $F_{k}=$ optimal fractions of wastewater that need to be treated (decision variable), $\left(D_{w w}\right)_{k}=$ total amount of wastewater reaching the decentralized treatment plant at the $k$ th location and $\theta=$ fraction of total water demand at any node that is non-potable, $\left(D_{w d}\right)_{k}=$ total water demand at all nodes associated with decentralized treatment plant at $k$.

As $R_{f}$ is the fraction of water supplied that comes out as wastewater, Equation (10) may be simplified as

$$
\left(Z_{d p}\right)_{k}=\left[\frac{\beta_{k} F_{k} \cdot R_{f}}{\theta}\right] \times\left(C_{p}\right)_{k} \times\left(L_{p}\right)_{k} .
$$

Approximate operation cost for the pumping of treated wastewater to households from the treatment plant at location $k$ is worked out based on the approximate pumping power $P_{k}$ (in $\left.\mathrm{kW}\right)$ required at that node.

$$
P_{k}=\frac{1.5 \times g \times\left[\beta_{k} \times F_{k} \times\left(D_{w w}\right)_{k}\right] \times\left(h_{p}\right)_{k}}{\eta}
$$

in which $\left(h_{p}\right)_{k}$ is the pumping head required at treatment plant $k$ and $\eta=$ pump efficiency. It may be noted that the power required is increased by $50 \%$ to account for uncertainty in these calculations. The Hazen-Williams equation is used for estimating the pumping head $\left(h_{p}\right)_{k}$.

$$
\left(h_{p}\right)_{k}=\left(h_{\text {addl }}\right)_{k}+\left(h_{\text {stat }}\right)_{k}+\frac{1.1 \times 10.678 \times\left[\beta_{k} \times F_{k} \times\left(D_{\text {www }}\right)_{k}\right]^{1.852} \times\left(L_{p}\right)_{k}}{C^{1.852} \times\left(D_{\text {nom }}\right)^{4.87}}
$$

in which $\left(h_{\text {stat }}\right)_{k}$ is the static head for pumping at location $k$, which may be obtained from the elevation difference between the highest point in that locality and the elevation of the place where the treatment plant is located. $C=$ Hazen-Williams coefficient for the pipeline, which depends on the pipe material. $D_{\text {nom }}=$ nominal diameter of the dual piping system considered for estimating the pumping cost. $\left(h_{\text {addl }}\right)_{k}=$ additional pumping head added as per local requirement. This considers the height of a local storage tank above the ground level at a representative node in that locality.

The pumping cost at any location $k,\left(Z_{\text {pump }}\right)_{k^{\prime}}$ is estimated using the following equation.

$$
\left(Z_{\text {pump }}\right)_{k}=C_{e} \times P_{k} \times T_{o p}+C R F \times C_{p} \times P_{k}
$$

in which $C_{e}=$ energy cost per one $\mathrm{kW}$ hour, $P_{k}=$ pumping power (see Equation (12)), $T_{o p}=$ total number of hours pump is operated in an year, $C R F=$ capital recovery factor (see Equation (4)), and $C_{p}=$ capital cost of pump per $\mathrm{kW}$. The calculation of the costs for fresh water, wastewater treatment, and reuse as well as for the unit costs for the treatment plants are carried out as described for the case of Model-1 in Equation (2). The same applies to the estimation of the flushing cost for sewers if the velocity becomes less than the self-cleansing velocity.

There is a cost-benefit $\left(z_{\text {treat }}\right)$ considered if the wastewater gets treated and not reused, because it is assumed that the treated wastewater is sold for the purpose of maintaining green areas

$$
\left(z_{\text {treat }}\right)_{k}=C_{s} \times\left(1-\beta_{k}\right) \times F_{k} \times\left(D_{w w}\right)_{k}
$$

in which $c_{s}$ is the unit price of treated wastewater sold for the maintenance of green areas.

The objective function in Model-2 minimizes the net total cost, $Z_{2}$, and can be stated as follows. 


$$
\begin{aligned}
Z_{2}=C_{f} \times\left[\sum_{i=1}^{N}\left(D_{t w}\right)_{i}-\sum_{k=1}^{N_{T}} \beta_{k} \times F_{k} \times\left(D_{w w}\right)_{k}\right]+C_{r} \times\left[\sum_{k=1}^{N_{T}} F_{k} \times\left(D_{w w}\right)_{k}\right]+\sum_{j=1}^{M} A_{j} \times V_{f l} \times t \times C_{f l} \times \delta_{j} \\
+C R F \times \sum_{k=1}^{N_{T}} C_{t p} \times X_{k}+C R F \times \sum_{k=1}^{N_{T}}\left[\frac{\beta_{k} \times F_{k} \times R_{f}}{\theta}\right] \times\left(C_{p}\right)_{k} \times\left(L_{p}\right)_{k}+\sum_{k=1}^{N_{T}} C_{e} \times P_{k} \times T_{o p} \\
+C R F \times \sum_{k=1}^{N_{T}} C_{p} \times P_{k}-C_{s} \times \sum_{k=1}^{N_{T}}\left(1-\beta_{k}\right) \times F_{k} \times\left(D_{w w}\right)_{k}
\end{aligned}
$$

In this model, the constraints are:

1. There may be an upper bound on the fraction of waste water that may be treated depending on the demand.

$$
F_{k} \leq F_{\max , k} \quad \forall k=1 \text { to } N_{T}
$$

2. There may be a constraint on the maximum amount of treated wastewater that can be supplied to households depending on the demand for non-potable water.

$$
\beta_{k} \leq \beta_{\text {max }, k} \quad \forall k=1 \text { to } N_{T}
$$

3. Although a flushing mechanism will be provided for all those sewers where the velocity $V_{p}$ is less than the self-cleansing velocity, still, a constraint is stipulated on the minimum velocity required.

$$
V_{p j} \geq V_{\min } \quad \forall j=1 \text { to } M
$$

4. As has been mentioned in the case of Model-1, we are interested in a screening model for use at the planning stage. It is assumed that pseudo steady uniform flow conditions exist during the peak flow. Velocities in each sewer for peak flow conditions are obtained by solving the Manning flow equation for free surface flow conditions. Therefore, the equality constraint for hydraulic conditions in each sewer as given in Equation (8) are applicable.

The flow rate in any sewer depends on the network connectivity (e.g., Figure 3), waste water input into the system at each node, and how much of this wastewater is treated at each of the decentralized locations. This equality constraint may be written as

$$
Q=g_{2}\left(\text { network connectivity, } R_{f} \times D_{t w}, F\right) \text {. }
$$

\subsection{Proposed Framework}

As the formulated optimization problem is non-linear, it is solved in this study using a simulation-optimization framework [39-41]. For optimization, the Genetic Algorithm is used from the MATLABC toolkit, with Population size = 50; Max Stall generations = 50, Max Generations $=200$, Function Tolerance $=0.1$, Constraint Tolerance $=0.01$, Crossover fraction $=0.8$, and Gaussian mutation function. Figure 4 shows the proposed simulationoptimization framework schematically. 


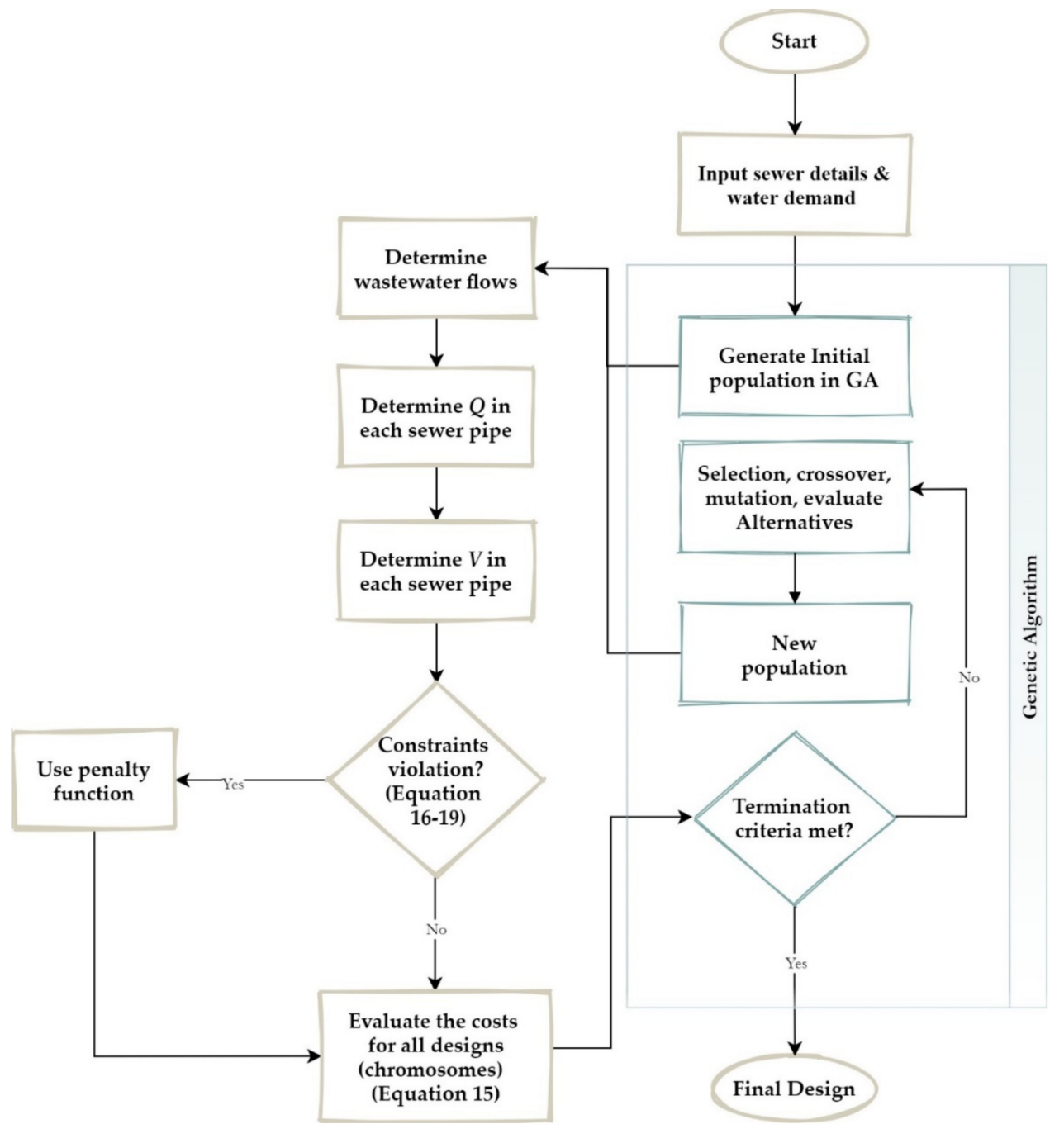

Figure 4. The proposed simulation-optimization framework.

\section{Results and Discussion}

The applicability of the proposed optimization models is illustrated in this section by applying them to two illustrative networks: one a proof-of-concept hypothetical network and the other a near realistic network, based on the sewerage network in the Indian Institute of Technology Madras, Chennai, India. The key takeaways obtained from each model application are discussed.

\subsection{Proof-of-Concept Network}

\subsubsection{Local On-Site Graywater Reuse}

The illustrative proof-of-the concept network is shown in Figure 1. Each node represents the point where wastewater enters into the network from the nearby residences. A population (number of people served) is assigned to each node to estimate the total water demand at that location as well as the amount of wastewater generated at that location. The nodes are also the sites for on-site graywater reuse. The sewerage system is a gravity flow separate system. Wastewater flows from all the nodes are directed toward the single centralized wastewater treatment plant, as shown in Figure 1. This sewerage system is assumed to exist, and we are interested in the optimal implementation of graywater reuse into this existing network.

The network details (population at each node; length, diameter, and slope of the links, and present velocity in each link) are provided in Table S1 in the Supplementary Materials. The total water demand at any node is $135 \mathrm{lpcd}$. Manning's roughness coefficient for all 
sewers $=0.015$. The upper and lower bounds on the fraction of graywater were set to $F_{\min }=0.2$ and $F_{\max }=0.8$ for the optimization. The other input required for application of the model is provided in Table 1. Values provided in Table 2 are chosen based on the prevailing costs in India and are decided after discussions with the Engineering Unit, which maintains and operates the sewerage system in IIT Madras. It should be noted that these values are only representative, taken here for illustration, and may vary from place to place. For example, in locations where water scarcity does not exist, the difference between unit costs of fresh water and recycled water may not be as high as taken here.

Table 1. Input data for the network in Figure 1 for graywater reuse.

\begin{tabular}{cc}
\hline Description & Values \\
\hline$C_{f}$ (unit cost of fresh water supply) & $₹ 100 / \mathrm{m}^{3}$ \\
$C_{r}$ (unit cost of reused water) & $₹ 18 / \mathrm{m}^{3}$ \\
$C_{f l}$ (unit cost of water used for flushing) & $₹ 18 / \mathrm{m}^{3}$ \\
Peak load factor & 3 \\
$R_{f}$ (wastewater conversion factor) & 0.9 \\
$\alpha$ (fraction of wastewater stream that is graywater) & 0.7 \\
$C_{t p}$ (unit cost for treatment plant) & $₹ 38,906 / \mathrm{m}^{3}$ \\
$V_{f l}$ (velocity provided during flushing) & $0.8 \mathrm{~m} / \mathrm{s}$ to $1 \mathrm{~m} / \mathrm{s}$ \\
$T_{f l}$ is the duration of flushing per day & $2 \mathrm{~min}$ to $20 \mathrm{~min}$ \\
Design period & 30 years \\
Interest rate & $12 \%$ \\
\hline
\end{tabular}

Table 2. Cost split up for implementation of local on-site graywater reuse: network in Figure 1.

\begin{tabular}{cc}
\hline Cost & Value (in ₹Annually) \\
\hline Cost of fresh water supply & $₹ 66.2 \mathrm{M}$ \\
Cost of treated graywater supply & $₹ 7.8 \mathrm{M}$ \\
Capital cost of treatment plant & $₹ 5.7 \mathrm{M}$ \\
Operation cost of the sewer & $₹ 2.8 \mathrm{M}$ \\
Total cost & $₹ 82.5 \mathrm{M}$ \\
\hline
\end{tabular}

The optimal fraction that should be reused at each site for the minimum total cost is shown in Figure 5. The total annualized cost of implementing the reusing system is ₹82.5 Million. The split up of total cost obtained using GA is shown in Table 3. The total cost of fresh water would be ₹109.4 Million in case the on-site graywater reusing is not introduced. There is a $24.6 \%$ percent reduction in the price paid for procuring water. Thus, the implementation of local on-site graywater treatment and reuse is economically feasible in this particular case. The results obtained showed that the implementation of local on-site graywater reuse reduces the demand for fresh water by $39 \%$.

Simulations are also made to obtain the cost of on-site graywater reuse assuming that a uniform fraction of graywater is reused at all the nodes. These simple forward simulations avoid the application of optimization procedures for the design. Results from such an exercise are presented in Table 3.

It can be observed from Table 3 that the least cost of implementation is obtained when $80 \%$ of graywater is treated uniformly at all the nodes. The cost of implementation for this case is ₹83.5 M. This is only marginally higher than the least cost obtained using the optimization model. However, this result cannot be generalized for all the networks because the total cost depends on various factors such as unit cost factors for treated and fresh water; cost of treatment plant; and the operation cost. The extra operational cost of the sewer network due to reduction in velocities is approximately $3.4 \%$. 


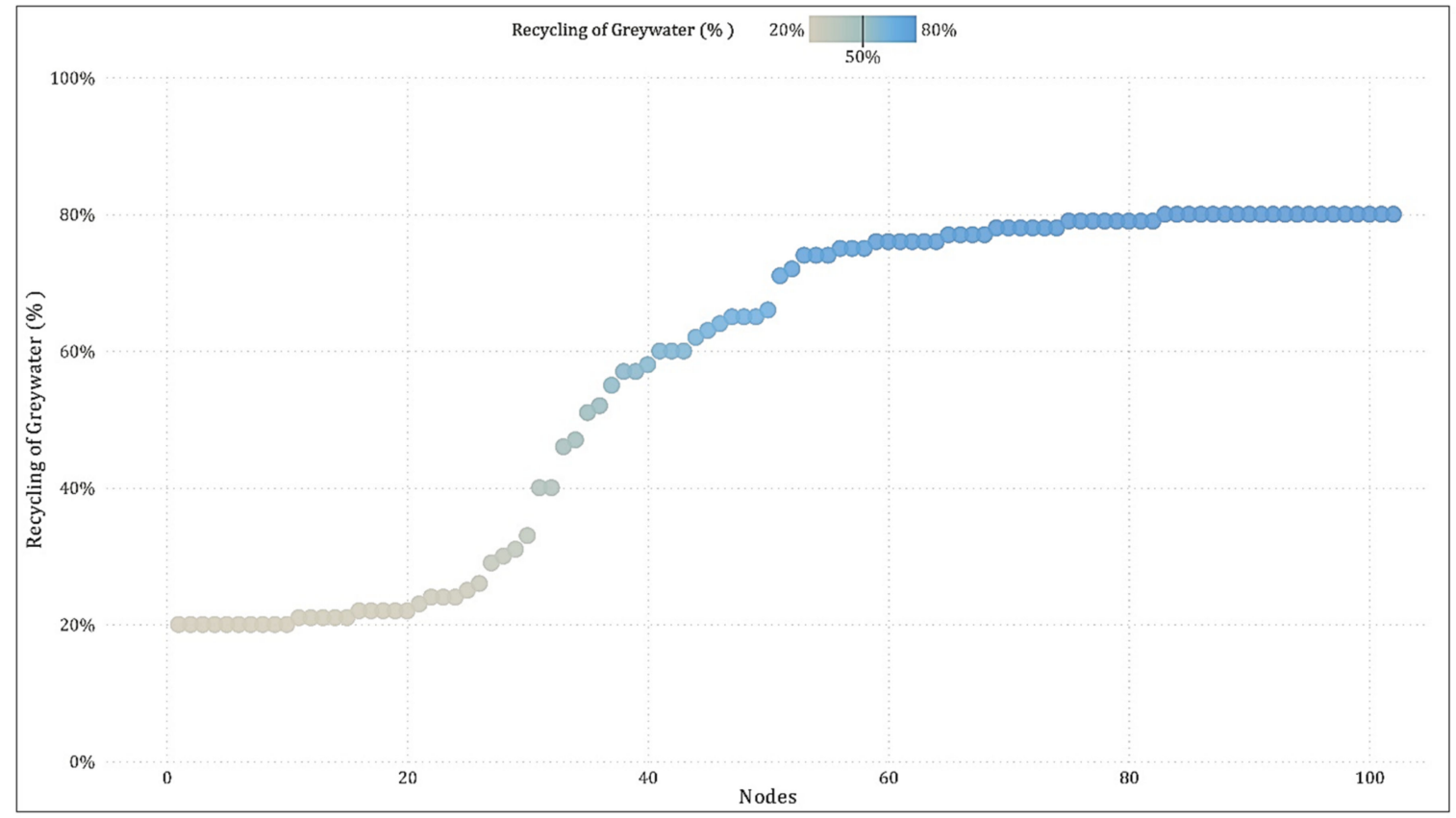

Figure 5. Optimal fractions of graywater treatment at each node: network in Figure 1.

Table 3. Cost of graywater reuse implementation for a constant fraction of treatment: network in Figure 1.

\begin{tabular}{cc}
\hline Uniform Fraction of Treatment & Total Cost \\
\hline 0.2 & $₹ 99.9 \mathrm{M}$ \\
0.3 & $₹ 95.5 \mathrm{M}$ \\
0.4 & $₹ 91.5 \mathrm{M}$ \\
0.5 & $₹ 88.2 \mathrm{M}$ \\
0.6 & $₹ 87.0 \mathrm{M}$ \\
0.7 & $₹ 87.2 \mathrm{M}$ \\
0.8 & $₹ 83.5 \mathrm{M}$ \\
\hline
\end{tabular}

\subsubsection{Decentralized Wastewater Reuse}

The illustrative proof-of-concept network is shown in Figure 3. Each node represents the point where wastewater enters into the network from the nearby residences. As earlier, population (number of people served) is assigned to each node to estimate the total water demand at that location as well as the amount of wastewater generated at that location. The sewerage system is a gravity flow separate system. This sewerage system is assumed to exist, and we are interested in the optimal implementation of decentralized waste water treatment and reuse into this existing network. The network details (population at each node; length, diameter, and slope of the links and present velocity in each link) are provided in Table S1. The total water demand at any node is 135 lpcd. Manning's roughness coefficient for all sewers $=0.015$. The upper and lower bounds on the fraction of wastewater were set to $F_{\text {min }}=0.2$ and $F_{\text {max }}=0.8$ for the optimization. The other input required for application of the model is provided in Table 4. In this problem, treated wastewater from a decentralized treatment plant is used for satisfying non-potable demand at all nodes upstream of that treatment plant and green area development in that locality.

The optimal fraction that should be treated at each of the available decentralized sites and the optimal fraction of the treated wastewater at each site that should be supplied to meet non-potable demand at the nodes are shown in Table 5. The remaining fraction of the treated wastewater at each of the decentralized site is sold for green area development, as shown in the Table 5. The split up of total cost obtained using green area after implementation of decentralized wastewater reusing is shown in Table 6. 
Table 4. Input values for decentralized wastewater treatment and reuse.

\begin{tabular}{|c|c|}
\hline Description & Values \\
\hline$C_{f}$ (unit cost of fresh water supply) & $₹ 100 / \mathrm{m}^{3}$ \\
\hline$C_{r}$ (unit cost of treated wastewater) & $₹ 30 / \mathrm{m}^{3}$ \\
\hline Peak factor & 3 \\
\hline$R_{f}$ (amount of water supplied that is converted to wastewater) & $90 \%$ \\
\hline$C_{t p}($ cost factor of treatment plant $)$ & $₹ 50,000 / \mathrm{m}^{3}$ \\
\hline$V_{f l}$ (velocity provided during flushing) & $0.8 \mathrm{~m} / \mathrm{s}$ to $1 \mathrm{~m} / \mathrm{s}$ \\
\hline$t_{f l}$ (duration of flushing) & $2 \mathrm{~min}$ to $20 \mathrm{~min}$ \\
\hline Design period & 30 years \\
\hline Interest rate & $12 \%$ \\
\hline \multirow{4}{*}{$\begin{array}{c}\text { Diameters of dual pipe line system which supplies treated waste water to nodes } \\
\text { (based on diameters used in reused water } \\
\text { distribution network in IIT Madras) }\end{array}$} & $200 \mathrm{~mm}$ DI at $₹ 2771 / \mathrm{m}$ \\
\hline & $150 \mathrm{~mm}$ DI at ₹2144/m \\
\hline & $140 \mathrm{~mm}$ HDPE at $₹ 1725 / \mathrm{m}$ \\
\hline & $110 \mathrm{~mm}$ HDPE at $₹ 1050 / \mathrm{m}$ \\
\hline Percentage distribution of diameter (Decentralized) in total supply length at each site. & $150 \mathrm{~mm} \mathrm{10 \% ;} 140 \mathrm{~mm} \mathrm{30 \% ;} 110 \mathrm{~mm} \mathrm{60 \% .}$ \\
\hline Percentage distribution of diameters (Centralized) in total supply length of network. & 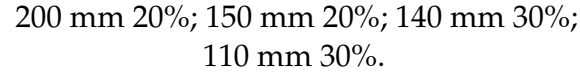 \\
\hline Energy cost & ₹ $6.5 / \mathrm{KWh}$ \\
\hline Pump efficiency & $75 \%$ \\
\hline Pumping duration & $24 \mathrm{~h}$ a day \\
\hline Hazen-Williams coefficient & 140 \\
\hline Stand by for peak discharge & $50 \%$ \\
\hline Additional head required & $\begin{array}{l}\text { Varies from } 15 \mathrm{~m} \text { to } 30 \mathrm{~m} \text { for } \\
\text { decentralized } \\
45 \mathrm{~m} \text { for centralized }\end{array}$ \\
\hline Cost of pumping unit & $₹ 21,300 / \mathrm{KW}$ \\
\hline$D_{\text {nom }}$ (nominal diameter for dual piping system) & $150 \mathrm{~mm}$ \\
\hline
\end{tabular}

Table 5. Optimal fraction for the treatment of wastewater for reuse: network in Figure 3.

\begin{tabular}{cccc}
\hline Site Location & \% Treated (Fk) & \% Reused $(\boldsymbol{\beta} \mathbf{k})$ & \% Sold \\
\hline 38 & 19.5 & 64.3 & 35.7 \\
45 & 17.1 & 89.9 & 10.1 \\
80 & 24.3 & 76.9 & 23.1 \\
51 & 25.1 & 84.2 & 15.8 \\
64 & 49.2 & 83.1 & 16.9 \\
55 & 43.9 & 85.6 & 14.4 \\
59 & 14.6 & 80.8 & 19.2 \\
\hline
\end{tabular}

Table 6. Annual cost split up for implementation of decentralized wastewater reuse: network in Figure 3.

\begin{tabular}{cc}
\hline Cost & Value \\
\hline Benefits & ₹4.54 M \\
Cost of supplied treated wastewater & $₹ 13.2 \mathrm{M}$ \\
Cost of fresh water supply & $₹ 72.8 \mathrm{M}$ \\
Pipe cost & $₹ 3.94 \mathrm{M}$ \\
treatment plant cost & $₹ 7.49 \mathrm{M}$ \\
Pumping cost (150 mm diameter) & $₹ 2.26 \mathrm{M}$ \\
Operation cost of the sewer & $₹ 1.26 \mathrm{M}$ \\
Total cost & $₹ 96.41 \mathrm{M}$ \\
\hline
\end{tabular}

The total price that would be paid annually for procuring fresh water is ₹ $109.4 \mathrm{M}$ if no wastewater reuse is carried out. The decentralized wastewater reusing can be implemented with a minimum annual cost of ₹96.41 M. Therefore, the implementation of decentralized wastewater treatment and reuse is economically feasible. Although the reduction in 
the price paid for procuring water is only $11.9 \%$, the results showed that the optimal implementation of decentralized wastewater treatment and reuse reduces the demand for fresh water by $34 \%$. The case of centralized wastewater treatment and then reuse with a dual piping system is also considered for the sake of comparison. The centralized model reduces the demand for fresh water by $50 \%$, but the overall cost of implementation is as high as ₹123.7 M. This significant difference in the cost arises in the centralized system in this particular case because of the need for pumping a large quantity of water from the most downstream point in the system. It may be noted that a further reduction in the implementation cost for both centralized and decentralized systems may be obtained by optimally designing the dual piping and pumping systems, along with solving for optimal fractions of treatment.

It is seen that for the particular network in consideration, the decentralized wastewater reuse model is more economical than the centralized wastewater treatment and reuse. However, the results obtained for this particular network cannot be generalized for all the networks. This is because the total cost depends on various factors such as unit cost for treated and fresh water, cost of treatment plant, the operation cost, cost of supply line, pumping cost, etc. Other parameters such as the dual pipeline cost differ from the centralized alternative to the decentralized model only when the households are distributed over a large area. It is expected that the dual pipeline cost will not differ significantly from the centralized to the decentralized alternative in small areas. The extra operational cost of the sewer network due to reduction in velocities is $1.31 \%$ w.r.t. to the total cost. This shows that the extra operation cost involved in decentralized reuse is very small in comparison to local on-site reuse.

\subsection{Realistic Network: IIT Madras Network}

\subsubsection{On-Site Graywater Reuse}

The optimization model for on-site graywater reuse is tested on a realistic sewerage network. This realistic sewerage network mostly resembles part of the larger sewerage network in the campus of The Indian Institute of Technology Madras (IIT Madras), Chennai India. IIT Madras is an autonomous public engineering and research institution located in Chennai (formerly Madras), Tamil Nadu, India. The total extent of the campus is 247 hectares (approximately $2.5 \mathrm{~km}^{2}$ ). The IIT Madras campus is divided into two zones, and the sewer network is designed independently for these two zones: Zone 1 and Zone 2. Herein, Zone 1 is selected for the demonstration of applicability of the optimization model for on-site graywater reuse because it is a larger network with more residential complexes and demand. The schematic of the network is shown in Figure 6. The network details (population at each node; length, diameter, and slope of the links and present velocity in each link) are provided in Table S2 in the Supplementary Materials. The network consists of 338 links and 115 nodes. The total population is 8743 . The data for the network are provided by the Engineering unit of IIT Madras. The sewerage system is a gravity flow separate system. Wastewater flows from all the nodes is directed toward the last node ' $\mathrm{CM}^{\prime}$ next to the wastewater treatment plant. All the other data given as input to the model are as given in Table 1.

The optimal fraction that should be reused at each node for the minimum total cost is demonstrated in Figure 7.

The split up of total cost for the optimal solution is presented in Table 7. The total fresh water bill without doing any reusing is ₹ $43.1 \mathrm{M}$ annually. The total cost obtained using the optimization model for on-site graywater reuse is ₹34.2 $\mathrm{M}$ annually. Thus, there is a $20.6 \%$ reduction in the cost of procuring water, and the implementation of local onsite graywater reuse is economically feasible. Simulations are also made to obtain the cost of on-site graywater reuse, assuming that a uniform fraction of graywater is reused at all the nodes. These simple forward simulations showed that the most economical implementation is to uniformly treat $50 \%$ of graywater that is generated at any node throughout the system (Table 8). The cost of implementation is ₹35.2 M. The results showed 
that the implementation of local on-site graywater reuse reduces the demand for fresh water by $36 \%$ if the proposed optimization model is used, while there is only a $31 \%$ reduction in case the treatment is uniform through the system. The extra operation cost of the sewer system is $5.32 \%$ of the total cost of implementation.

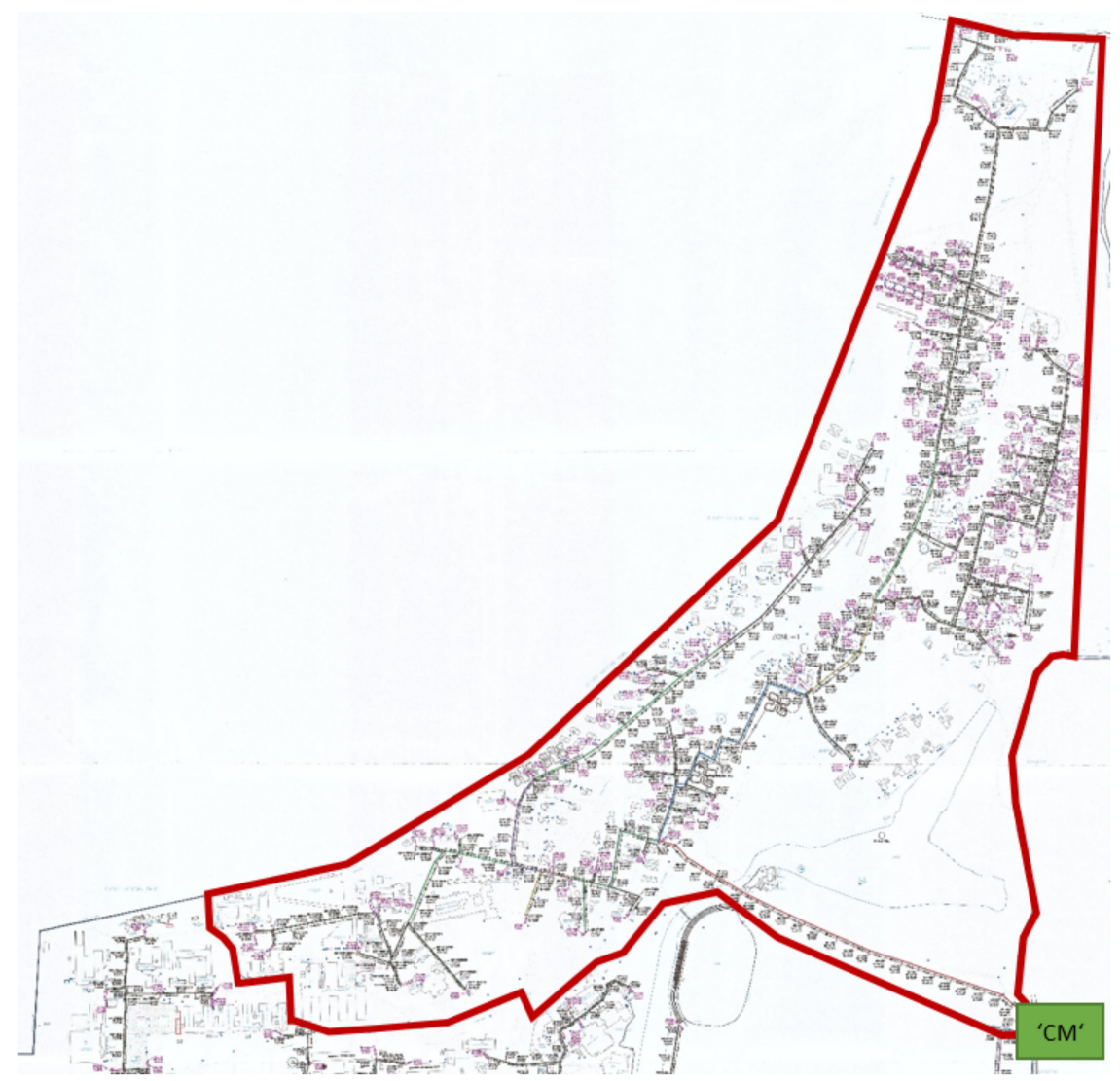

Figure 6. Sewerage network in IIT Madras (region above the green line is Zone 1).

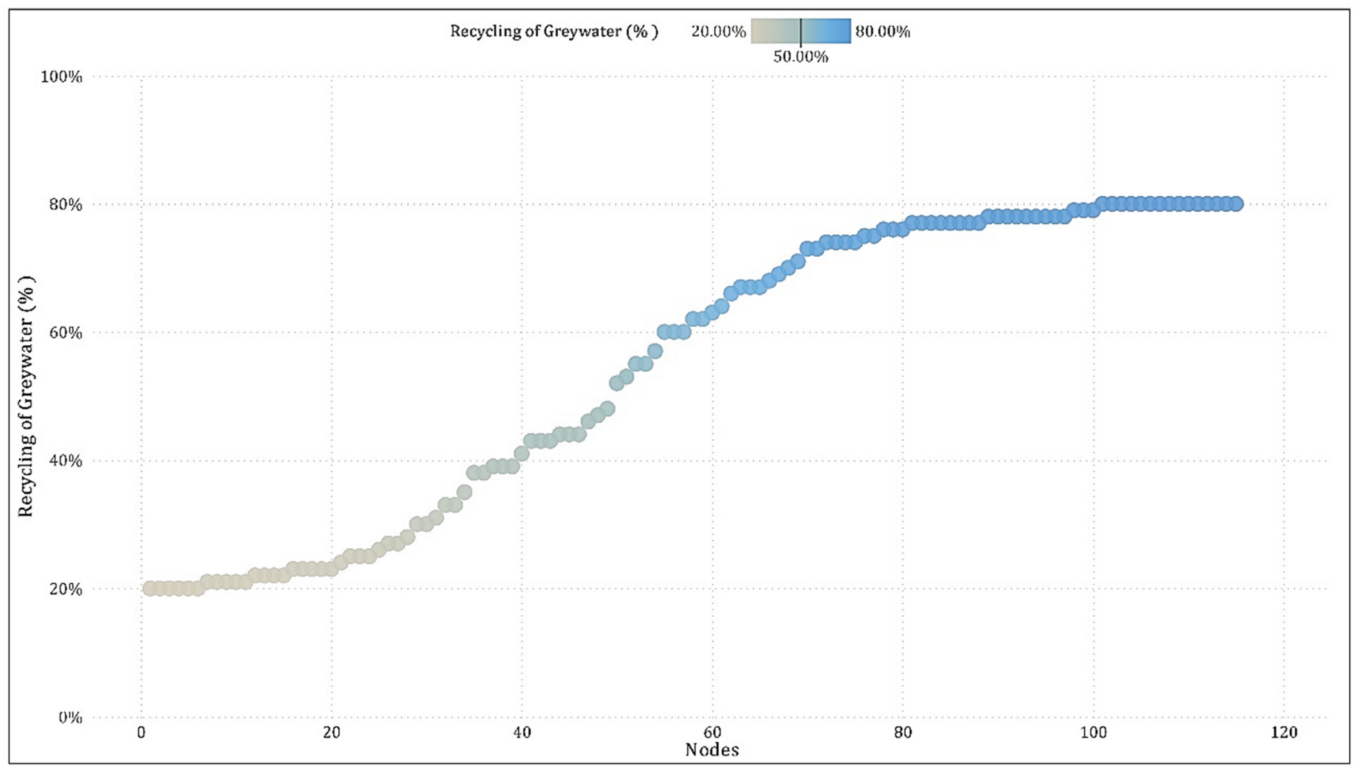

Figure 7. Optimal fractions of graywater treatment at each node: IIT Madras network (node number identification is given in Table S3 in the Supplementary Materials). 
Table 7. Cost split up for implementation of local on-site graywater reuse: IIT Madras network.

\begin{tabular}{cc}
\hline Cost & Value (in ₹Annually) \\
\hline Cost of fresh water supply & $₹ 27.50 \mathrm{M}$ \\
Cost of treated graywater supply & $₹ 2.80 \mathrm{M}$ \\
Capital cost of treatment plant & $₹ 2.06 \mathrm{M}$ \\
Operation cost of the sewer & $₹ 1.82 \mathrm{M}$ \\
Total cost & $₹ 34.18 \mathrm{M}$ \\
\hline
\end{tabular}

Table 8. Cost of graywater reuse implementation for a constant fraction of treatment: IIT Madras network.

\begin{tabular}{cc}
\hline Uniform Fraction of Treatment & Total Cost \\
\hline 0.2 & $₹ 39.3 \mathrm{M}$ \\
0.3 & $₹ 38.0 \mathrm{M}$ \\
0.4 & $₹ 36.8 \mathrm{M}$ \\
0.5 & $₹ 35.2 \mathrm{M}$ \\
0.6 & $₹ 35.5 \mathrm{M}$ \\
0.7 & $₹ 36.3 \mathrm{M}$ \\
0.8 & $₹ 36.8 \mathrm{M}$ \\
\hline
\end{tabular}

\subsubsection{Decentralized Wastewater Reuse}

The schematic of the network is shown in Figure 6. The network details (population at each node; length, diameter, and slope of the links, and present velocity in each link) are provided in Table S2 in the Supplementary Materials. Herein, we assume that space is available at three sites, 139, 161, and 65, for the installation of decentralized wastewater treatment plants. Populations being served by each of these sites are 3510, 2451, and 2872 persons at sites 139, 161, and 65, respectively. All the other data given as input to the model are shown in Table 4. Demand input to the model is based on the population that is served by each site. The maximum non-potable water demand is taken as $50 \%$ and the green area requirement is taken as $15 \%$ of the fresh water demand at the site. The optimal fraction that should be treated at each of the available decentralized sites and the optimal fraction of the treated wastewater at each site that should be supplied to meet nonpotable demand at the nodes are shown in Table 9. The remaining fraction of the treated wastewater at each of the decentralized site is sold for green area development, as shown in Table 9. The split up of total cost for implementation obtained using the optimization model is shown in Table 10. In this system, the nominal diameter for pumping the treated wastewater is $110 \mathrm{~mm}$.

Table 9. Optimal fraction for treatment of wastewater for reuse: IIT Madras network.

\begin{tabular}{cccc}
\hline Site Location & \% Treated $\left(\boldsymbol{F}_{\boldsymbol{k}}\right)$ & \% Reused $\left(\boldsymbol{\beta}_{\boldsymbol{k}}\right)$ & \% Sold \\
\hline 139 & 16.8 & 98.6 & 1.4 \\
161 & 26.2 & 97.3 & 2.7 \\
65 & 21.9 & 99.6 & 0.4 \\
\hline
\end{tabular}

Table 10. Annual cost split up for implementation of decentralized wastewater reuse: IIT Madras network.

\begin{tabular}{cc}
\hline Cost & Value (M) \\
\hline Benefits & $₹ 0.14$ \\
Cost of supplied treated wastewater & $₹ 4.62$ \\
Cost of fresh water supply & $₹ 27.90$ \\
Pipe cost & $₹ 1.01$ \\
treatment plant cost & $₹ 2.62$ \\
Pumping cost (150 mm diameter) & $₹ 0.53$ \\
Operation cost of the sewer & $₹ 0.58$ \\
Total cost & $₹ 37.26$ \\
\hline
\end{tabular}


The total fresh water bill without doing any reusing is ₹43.1 M. The total cost obtained using the optimization model is GA is ₹37.26 M annually. With a cost reduction of 13.5\%, the implementation of decentralized wastewater treatment and reuse is economically feasible, and at the same time, the fresh water demand is reduced by $35 \%$. Simulations are also made for the case of centralized wastewater treatment and reuse via a dual piping system. The cost of implementation for such a scenario is ₹38.9 M annually, which is only marginally more than that for the case of decentralized wastewater treatment and reuse. This result is understandable, because the areal extent of the network is small and the total population being served is also small. In fact, our simulations have shown that the cost of the centralized system is reduced further to ₹35.2 M annually, if the nominal diameter of the dual piping system for pumping the treated wastewater is taken as $150 \mathrm{~mm}$ instead of $110 \mathrm{~mm}$. These results indicate the importance of integrated optimal solutions for sizing the dual piping system along with solving for optimal fractions of treatment. These studies are currently underway by the authors.

\section{Conclusions and Outlook}

In this study, two optimization models for integrating reuse systems into existing sewerage systems to bridge the supply-demand gap in an existing water supply system have been developed. In the first model, the supply-demand gap is bridged by introducing on-site graywater treatment and reuse and in the second model by decentralized wastewater treatment and the reuse and implementation of a dual piping system. The applicability of the proposed models is tested using two case studies: (1) a proof-of-concept hypothetical network and (2) a near-realistic network, based on the sewerage network in the Indian Institute of Technology Madras, Chennai, India. The following conclusions can be derived from the results of the case studies. The following list also contains the potential topics for future studies.

- The results showed that the optimal implementation of graywater reuse into this existing network can significantly reduce the price paid for procuring water, taking into account the underlying cost rates $(24.6 \%$ for the first test case and $20.6 \%$ for the second one).

- This optimal integration also can reduce the fresh water demand by $39 \%$ and $36 \%$ for the first and second test case, respectively.

- The optimal implementation of decentralized wastewater reuse into this existing network reduced the water price by $11.9 \%$ for the first test case and $13.5 \%$ for the second one, which is much less than the optimal implementation of graywater reuse for our particular case studies.

- To avoid the application of optimization procedures for the design of on-site graywater reuse, a simple approach that assumes a uniform fraction of graywater is reused at all the nodes is tested. The results of this approach were only marginally higher than the least cost obtained using the optimization model.

- $\quad$ The cost of implementing centralized wastewater treatment and then reusing with a dual piping system was marginally higher than decentralized wastewater reuse, but this alternative can save up to $50 \%$ of fresh water.

- We considered a fixed price for fresh water over time. New analysis and predicting the price of fresh water in the future can influence the results of this study.

- The results of this study are case-dependent and cannot be directly transferred to another area with different specifications.

- The integrated optimization model for sizing the dual piping system along with solving for optimal fractions of treatment is suggested.

- The integrated optimization models that can simultaneously optimize and design decentralized urban drainage systems, water distribution networks, and treatment facilities for green field planning is another exciting research topic for the future. 
Supplementary Materials: The following are available online at https: / www.mdpi.com/article/ 10.3390/w13152004/s1, Table S1: Network details for the network in Figure 1, Table S2: Network Details for IIT Madras network, Table S3: Identification of Nodes: IIT Madras network.

Author Contributions: Conceptualization, S.M.B., T.C.D., A.E.B. and U.D.; methodology, S.M.B., T.C.D., A.E.B. and U.D.; software, A.D., S.M.B., A.E.B. and T.C.D.; validation, A.D., S.M.B. and A.E.B.; formal analysis, A.D., A.E.B. and T.C.D.; investigation, A.D.; resources, S.M.B.; data curation, A.D.; writing-original draft preparation, A.E.B.; writing-review and editing, T.C.D., S.M.B., U.D. and A.D.; visualization, A.E.B.; supervision, S.M.B., T.C.D. and U.D.; project administration, S.M.B. and U.D.; funding acquisition, U.D. and S.M.B. All authors have read and agreed to the published version of the manuscript.

Funding: The research was carried out as part of Indo-German research project Smart \& Wise. The project was funded by the Indo-German Science \& Technology Centre (IGSTC) established by the Department of Science and Technology (DST), Government of India and the Federal Ministry of Education and Research (BMBF). The scientific collaboration for this work was additionally supported by the Indo-German Center for Sustainability (stay of TCD at IIT Madras) and Center of Excellence SUTRAM for EASY Water established by Water Technology Institute of DST, Govt. of India.

Institutional Review Board Statement: Not applicable.

Informed Consent Statement: Not applicable.

Data Availability Statement: The data presented in this study are openly available in the Supplementary Materials.

Acknowledgments: The authors thank Ligy Philip of IIT Madras for the many fruitful discussions, especially while formulating the problem and Vineeth, $\mathrm{P}$ who carried out initial simulation runs when he was an intern at IIT Madras.

Conflicts of Interest: The authors declare no conflict of interest.

\section{References}

1. Water Aid India. State of Urban Water Supply in India-2018; Exhibitions India Group: New Delhi, India, 2018.

2. Xiong, J.; Hswen, Y.; Naslund, J.A. Digital surveillance for monitoring environmental health threats: A case study capturing public opinion from Twitter about the 2019 Chennai water crisis. Int. J. Environ. Res. Public Health 2020, 17, 5077. [CrossRef] [PubMed]

3. Mekonnen, M.M.; Hoekstra, A.Y. Four billion people facing severe water scarcity. Sci. Adv. 2016, 2, e1500323. [CrossRef]

4. TERI. The Energy Research Institute (TERI). Available online: https://www.teriin.org/resilient-cities/urbanisation.php (accessed on 3 December 2020).

5. Butler, D.; Farmani, R.; Fu, G.; Ward, S.; Diao, K.; Astaraie-Imani, M. A new approach to urban water management: Safe and sure. Procedia Eng. 2014, 89, 347-354. [CrossRef]

6. Leigh, N.; Lee, H. Sustainable and resilient urban water systems: The role of decentralization and planning. Sustainability 2019, 11, 918. [CrossRef]

7. Brown, R.; Ashley, R.; Farrelly, M. Political and professional agency entrapment: An agenda for urban water research. Water Resour. Manag. 2011, 25, 4037-4050. [CrossRef]

8. Sitzenfrei, R.; Moderl, M.; Rauch, W. Assessing the impact of transitions from centralised to decentralised water solutions on existing infrastructures-Integrated city-scale analysis with VIBe. Water Res. 2013, 47, 7251-7263. [CrossRef]

9. Bakhshipour, A.E.; Dittmer, U.; Haghighi, A.; Nowak, W. Towards sustainable urban drainage infrastructure planning: A combined multiobjective optimization and multicriteria decision-making platform. J. Water Resour. Plan. Manag. $2021,147$. [CrossRef]

10. Eggimann, S.; Truffer, B.; Maurer, M. To connect or not to connect? Modelling the optimal degree of centralisation for wastewater infrastructures. Water Res. 2015, 84, 218-231. [CrossRef] [PubMed]

11. Bakhshipour, A.E.; Bakhshizadeh, M.; Dittmer, U.; Haghighi, A.; Nowak, W. Hanging gardens algorithm to generate decentralized layouts for the optimization of urban drainage systems. J. Water Resour. Plan. Manag. 2019. [CrossRef]

12. Poustie, M.S.; Deletic, A.; Brown, R.R.; Wong, T.; de Haan, F.J.; Skinner, R. Sustainable urban water futures in developing countries: The centralised, decentralised or hybrid dilemma. Urban Water J. 2014, 12, 543-558. [CrossRef]

13. Sitzenfrei, R.; Rauch, W. Investigating transitions of centralized water infrastructure to decentralized solutions-An integrated approach. Procedia Eng. 2014, 70, 1549-1557. [CrossRef]

14. Schuetze, T.; Chelleri, L. Integrating decentralized rainwater management in urban planning and design: Flood resilient and sustainable water management using the example of coastal cities in The Netherlands and Taiwan. Water 2013, 5, 593-616. [CrossRef] 
15. Oberascher, M.; Kinzel, C.; Kastlunger, U.; Kleidorfer, M.; Zingerle, C.; Rauch, W.; Sitzenfrei, R. Integrated urban water management with micro storages developed as an IoT-based solution-The smart rain barrel. Environ. Model. Softw. 2021, 139, 105028. [CrossRef]

16. Bakhshipour, A.E.; Dittmer, U.; Haghighi, A.; Nowak, W. Hybrid green-blue-gray decentralized urban drainage systems design, a simulation-optimization framework. J. Environ. Manag. 2019, 249, 109364. [CrossRef]

17. Raei, E.; Reza Alizadeh, M.; Reza Nikoo, M.; Adamowski, J. Multi-objective decision-making for green infrastructure planning (LID-BMPs) in urban storm water management under uncertainty. J. Hydrol. 2019, 579, 124091. [CrossRef]

18. Di Matteo, M.; Maier, H.R.; Dandy, G.C. Many-objective portfolio optimization approach for stormwater management project selection encouraging decision maker buy-in. Environ. Model. Softw. 2019, 111, 340-355. [CrossRef]

19. Bach, P.M.; Deletic, A.; Urich, C.; Sitzenfrei, R.; Kleidorfer, M.; Rauch, W.; McCarthy, D.T. Modelling interactions between lot-scale decentralised water infrastructure and urban form-A case study on infiltration systems. Water Resour. Manag. 2013, 27, 4845-4863. [CrossRef]

20. Spuhler, D.; Scheidegger, A.; Maurer, M. Generation of sanitation system options for urban planning considering novel technologies. Water Res. 2018, 145, 259-278. [CrossRef]

21. Massoud, M.A.; Tarhini, A.; Nasr, J.A. Decentralized approaches to wastewater treatment and management: Applicability in developing countries. J. Environ. Manag. 2009, 90, 652-659. [CrossRef] [PubMed]

22. Dilly, T.C.; Baron, S.; Schmitt, T.G.; Holzhauser, M.; Hoek, J.; Schöffel, S.; Schwank, J. Transformation strategies for wastewater systems under uncertain conditions. In Proceedings of the 14th IWA/IAHR International Conference on Urban Drainage, Prague, Czech Republic, 12 September 2017.

23. Schramm, E.; Felmeden, J. Towards more resilient water infrastructures. In Resilient Cities 2; Otto-Zimmermann, K., Ed.; Springer: Dordrecht, The Netherlands, 2012; pp. 177-186, ISBN 978-94-007-4222-2.

24. Sapkota, M.; Arora, M.; Malano, H.; Moglia, M.; Sharma, A.; George, B.; Pamminger, F. An overview of hybrid water supply systems in the context of urban water management: Challenges and opportunities. Water 2015, 7, 153-174. [CrossRef]

25. Little, R.G. Controlling cascading failure: Understanding the vulnerabilities of interconnected infrastructures. J. Urban Technol. 2002, 9, 109-123. [CrossRef]

26. Mandal, D.; Labhasetwar, P.; Dhone, S.; Dubey, A.S.; Shinde, G.; Wate, S. Water conservation due to greywater treatment and reuse in urban setting with specific context to developing countries. Resour. Conserv. Recycl. 2011, 55, 356-361. [CrossRef]

27. Tortajada, C.; van Rensburg, P. Drink more recycled wastewater. Nature 2020, 577, 26-28. [CrossRef] [PubMed]

28. Voulvoulis, N. Water reuse from a circular economy perspective and potential risks from an unregulated approach. Curr. Opin. Environ. Sci. Health 2018, 2, 32-45. [CrossRef]

29. Nika, C.E.; Gusmaroli, L.; Ghafourian, M.; Atanasova, N.; Buttiglieri, G.; Katsou, E. Nature-based solutions as enablers of circularity in water systems: A review on assessment methodologies, tools and indicators. Water Res. 2020, $183,115988$. [CrossRef]

30. Yoonus, H.; Al-Ghamdi, S.G. Environmental performance of building integrated grey water reuse systems based on Life-Cycle Assessment: A systematic and bibliographic analysis. Sci. Total Environ. 2020, 712, 136535. [CrossRef]

31. Penn, R.; Schütze, M.; Friedler, E. Modelling the effects of on-site greywater reuse and low flush toilets on municipal sewer systems. J. Environ. Manag. 2013, 114, 72-83. [CrossRef]

32. Penn, R.; Hadari, M.; Friedler, E. Evaluation of the effects of greywater reuse on domestic wastewater quality and quantity. Urban Water J. 2012, 9, 137-148. [CrossRef]

33. Penn, R.; Schütze, M.; Friedler, E. Assessment of the effects of greywater reuse on gross solids movement in sewer systems. Water Sci. Technol. 2014, 69, 99-105. [CrossRef] [PubMed]

34. Penn, R.; Schütze, M.; Alex, J.; Friedler, E. Impacts of onsite greywater reuse on wastewater systems. Water Sci. Technol. 2017, 75, 1862-1872. [CrossRef]

35. Penn, R.; Friedler, E.; Ostfeld, A. Multi-objective evolutionary optimization for greywater reuse in municipal sewer systems. Water Res. 2013, 47, 5911-5920. [CrossRef]

36. Zhang, W.; Wang, C.; Li, Y.; Wang, P.; Wang, Q.; Wang, D. Seeking sustainability: Multiobjective evolutionary optimization for urban wastewater reuse in China. Environ. Sci. Technol. 2014, 48, 1094-1102. [CrossRef] [PubMed]

37. Newman, J.P.; Dandy, G.C.; Maier, H.R. Multiobjective optimization of cluster-scale urban water systems investigating alternative water sources and level of decentralization. Water Resour. Res. 2014, 50, 7915-7938. [CrossRef]

38. Basupi, I. Design of integrated water systems: Water distribution system, household water-saving scheme, and sanitary sewer perspectives. J. Water Resour. Plan. Manag. 2021, 147, 4020102. [CrossRef]

39. Haghighi, A.; Bakhshipour, A.E. Optimization of sewer networks using an adaptive genetic algorithm. Water Resour. Manag. 2012, 26, 3441-3456. [CrossRef]

40. Maier, H.R.; Razavi, S.; Kapelan, Z.; Matott, L.S.; Kasprzyk, J.; Tolson, B.A. Introductory overview: Optimization using evolutionary algorithms and other metaheuristics. Environ. Model. Softw. 2019, 114, 195-213. [CrossRef]

41. Akella, C.S.; Bhallamudi, S.M. Managing municipal wastewater treatment to control nitrous oxide emissions from Tidal rivers. Water 2019, 11, 1255. [CrossRef] 